\title{
Wave generation in an OWC system for wave energy conversion
}

\author{
Bouhrim Hafsa, El Marjani Abdellatif*, and Hamid Mounir \\ EMISys Research Team, Turbo machinery Lab, Mohammadia School of Engineers, Mohammed V-University in Rabat, Avenue Ibn \\ Sina, BP 765, Agdal, Rabat, Morocco
}

\begin{abstract}
This paper aims to present an overview on the wavemakers used to generate waves inside a numerical wave tank taking into consideration the biphasic air-water aspect of the incident wave. Wave markers are used to simulate the flow dynamic behaviour in the Oscillating Water Column (OWC) for wave energy conversion. Three kinds of these systems have been considered in the present work. To compare these types of wave generators a case study was adopted with the assumption of a fluid flow which is unsteady, 2D, biphasic (air-water), and k-epsilon turbulent. It has been found that the piston and the flap wave maker types are suitable for OWC device simulations.
\end{abstract}

\section{NOMENCLATURE}

$\begin{array}{cl}\text { T } & \text { Wave period } \\ \mathrm{H} & \text { Wave height } \\ \mathrm{d} & \text { Water depth } \\ \lambda & \text { Wave length } \\ \mathrm{L} & \text { Wave tank length } \\ \mathrm{h} & \text { Wave tank height } \\ \mathrm{e} & \text { OWC duct } \\ \mathrm{S} & \text { The stroke } \\ \mathrm{V} & \text { Velocity in } \mathrm{x} \text {-direction } \\ \omega & \text { The angular frequency }\end{array}$

\section{INTRODUCTION}

Wave energy stands out among the most relevant renewable and sustainable energy resources; This explains the great research and development efforts made in the field of wave energy exploitation, which produced many designs and technologies classified as mentioned in [1]; devices off-shore, near shore, and on shore. Another way to classify the wave energy converters is based on their operating principle: OWCdevices, Surging devices, Overtopping devices [2].

The oscillating water column OWC devices are the most widely used types of wave energy conversion technologies, due to their low operational and maintenance costs. The OWC system consists mainly of two essential components, the air chamber and the air turbine. Basically, the device concept consists of a submerged air chamber connected to the atmosphere by means of a circular duct inside which a bidirectional flow turbine is installed. The flow rate of air through the turbine is created by the successive incident sea water waves that compress and depressurize air in the chamber by means of the periodic motion of the oscillating free surface. The conversion of this air flow into mechanical energy may be reached by means of a number of devices Figure 1.

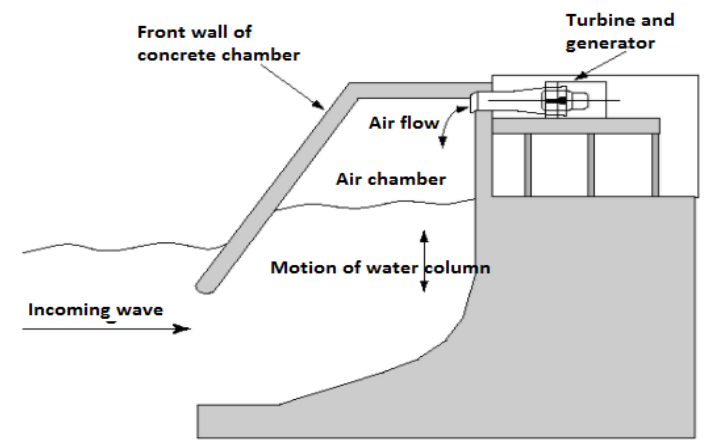

Fig.1 Oscillating water column device (OWC)

In many studies the OWC, efficiency improvement was only focused on the air flow field inside the chamber as in $[3,4]$. However, recent researches in wave energy conversion domain have focused on experimental analyses using numerical wave tanks (NWT) for flow characteristics prediction in OWC systems with the help of CFD methods. The NWT system is based on the VOF model to generate the incoming incident wave by either employing the Reynolds Navier Stokes model as in [5] or a velocity potential approach $[6,7]$.

The aim of the present study is to compare regular wave generation inside a 2-dimensional numerical wave tank using three types of wavemakers as indicated in Figure 2. For this, Computational fluid dynamics CFD was used to simulate the air flow behavior, and the multiphase VOF model was used to analyze the biphasic (air-water) aspect of the water's free surface inside the wave tank.

\footnotetext{
* Corresponding author: marjani.abdel@gmail.com
} 


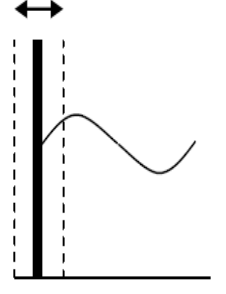

Piston type
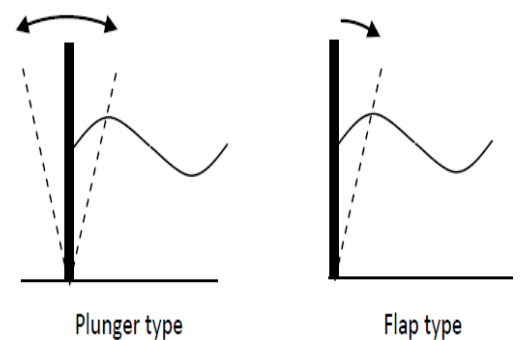

Flap type
Fig.2 Wavemaker types

\section{THE WAVE TANK MODEL}

\subsection{Wavemaker Theory}

In order to produce the desired incident waves in experimental tests, the wave generators or (wave makers) are strongly recommended. The principle of the wavemaker theory is based on relating the water free surface motion to the displacement of the wavemaker, an overview of the different wavemakers is provided in $[8,9]$.

In what follows, a brief description of the well commonly used wave generators will be presented and discussed.

\subsubsection{Piston wavemakers}

These types are used in case of shallow waters for which the particle motion is compressed into an ellipse and significant horizontal motion of the wave tank is noticed. As indicated by [10] the quantity of water displaced by the vertical piston oscillating in the horizontal direction with a stroke $\mathrm{S}$ is equal to the quantity of water contained in the crest of a propagating wave Figure 3.

$$
\int_{0}^{\pi / 2} \frac{H}{2} \cdot \sin \left(\frac{2 \pi}{L} x\right) d x=S h
$$

The stroke $\mathrm{S}$ is obtained by evaluating the Eq.1 which gives:

- For shallow water:

$$
\left(\frac{H}{S}\right)_{\text {piston }}=k h
$$

Where: denotes the wave number.

- For deep water:

$$
\left(\frac{H}{S}\right)_{\text {piston }}=\frac{4 \sinh ^{2}(k h)}{\sinh (2 k h)+2 k h}
$$

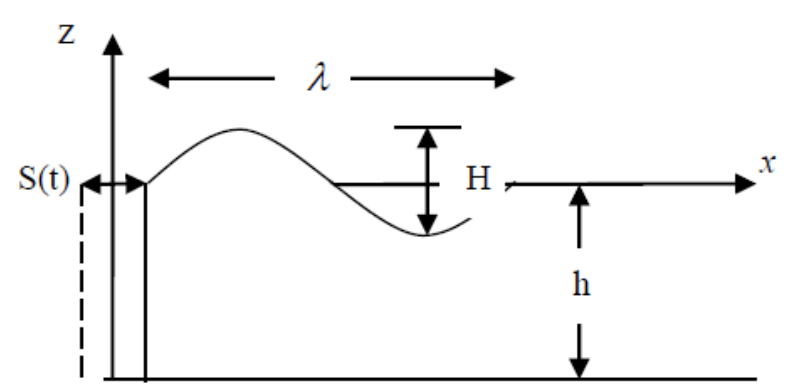

Fig.3 Piston Type Wavemaker

This type of wave generators are also used for wave generation in coastal structure modelings, harbors and shore mounted wave energy devices.

\subsubsection{Flap wave generators}

These types are used for wave generation in deep waters for which the orbital particle motion is impacted by the water depth and where negligible motion at the bottom is noticed Figure 4. The values of stroke obtained for the present wave generators is as follows [11]:

- For shallow water:

$$
\left(\frac{H}{S}\right)_{\text {flap }}=\frac{k h}{2}
$$

- For deep water:

$$
\left(\frac{H}{S}\right)_{\text {flap }}=\frac{4 \sinh (k h)}{\sinh (2 k h)+2 k h}\left[\sinh (k h)+\frac{1-\cosh (k h)}{k h}\right]
$$

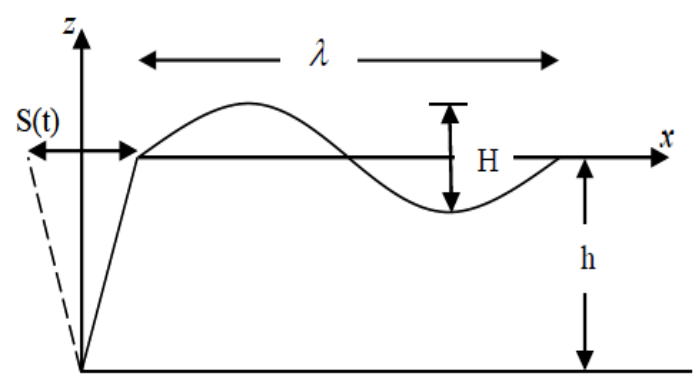

Fig.4 flap type wavemaker

Some of the uses of this type is for ocean waves physics investigating and floating structures modelling in deep waters.

\subsubsection{Plunger wavemakers}

Consist of a rigid body oscillating vertically in one side of a wave tank about the mean water level, as performed in Figure 5. 


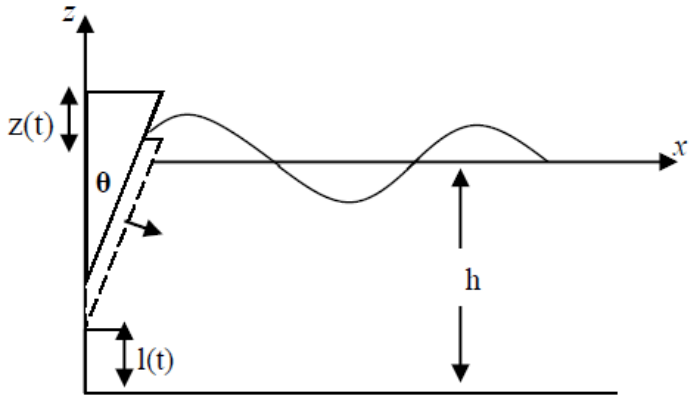

Fig.5 Plunger Type wavemaker

Plunger wave generators are commonly employed in case of wave basins because they are easily relocated within the basin and they can be fabricated as fairly long wave machines.

\subsection{VOF Methodology}

The multiphase VOF methodology enables to model two or more immiscible fluid phases by tracking the volume fraction of each fluid phase in a computational cell [8]. In the current paper, the main goal of the VOF method is to analyze the biphasic (air-water) aspect of the water's free surface inside the wave tank. The principle is based on the volume fraction in each cell which is comprised between 0 and 1. Basically, the following three conditions for a two phase (air and water) model with air $\alpha_{\text {air }}$ the air volume fraction are verified:

$$
\begin{cases}\alpha_{\text {air }}=1 & \text { Cell full of air } \\
\alpha_{\text {air }}=0 & \text { Cell full of water } \\
0 \prec \alpha_{\text {air }} \prec 1 & \begin{array}{l}
\text { Cell contain the interface between } \\
\text { air and water }
\end{array}\end{cases}
$$

\section{STUDY CASE}

\subsection{Computational Domain}

The computational domain used in the current work is performed in Figure 6 in which the geometry dimensions are chosen so that they take into account the incident wave characteristics in terms of wave height $(\mathrm{H})$, wave period $(\mathrm{T})$, and water depth (d).

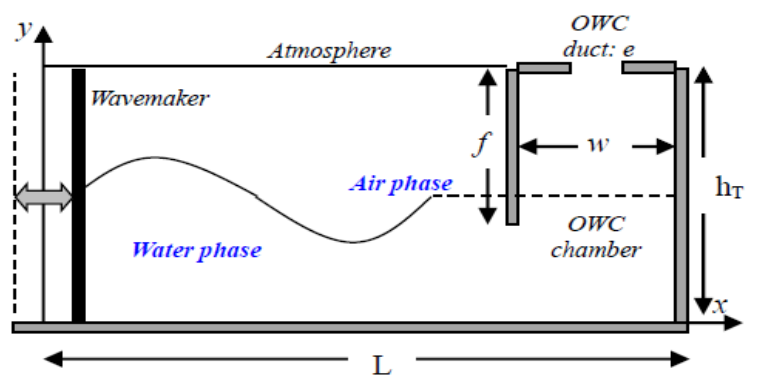

Fig.6 Numerical domain corresponding to the current case study

In order to avoid the wave reflection, the wave tank length (L) is taken as five times the wave length $(\lambda)$. For the wave tank height, both the wave height and the propagation depth are combined. So, the wave tank height is three times the wave height plus the propagation depth. The dimensions of the wave tank are listed in Table 1.

Table 1. Characteristic dimensions of the problem

\begin{tabular}{|c|c|}
\hline Parameters & Values \\
\hline $\mathrm{T}$ & $2 \mathrm{~s}$ \\
\hline $\mathrm{H}$ & $0.06 \mathrm{~m}$ \\
\hline$\lambda$ & 3.82 \\
\hline $\mathrm{h}_{\mathrm{T}}$ & $0.74 \mathrm{~m}$ \\
\hline $\mathrm{e}$ & $0.004 \mathrm{~m}$ \\
\hline $\mathrm{w}$ & $0.12 \mathrm{~m}$ \\
\hline $\mathrm{f}$ & $0.5 \mathrm{~m}$ \\
\hline
\end{tabular}

Where the value of wavelength $\lambda$ in Table 1 . Is calculated using the dispersion relation given by:

$$
\lambda^{2}=\frac{g T^{2}}{2 \pi} \tanh \left(\frac{2 \pi d}{\lambda}\right)
$$

\subsection{Boundary Conditions}

The horizontal motion of the incident wave is generated by use of a wave maker which placed at the left side of the wave tank Figure 3. Simulation of the wave maker in CFD computations is assured by using the dynamic mesh method in the area of moving boundary to enable the variation of velocity profile which is described by a user defined function (UDF). Thanks to this theory it's possible to identify the displacement $\mathrm{v}$ of the piston using the following relations given in [10] for a 2D potential flow theory:

$$
v(t)=\frac{S \omega}{2} \cos (\omega t)
$$

The other boundary conditions consist of an atmospheric pressure applied at both the top opening of the NWT, and the outlet of the OWC chamber, with a 
value corresponding to gauge pressure (zero). At the bottom of the NWT the wall is considered as no-slip.

Table 1. Boundary Conditions

\begin{tabular}{|c|c|}
\hline Region & Boundary Conditions \\
\hline $\begin{array}{c}\text { Atmosphere and OWC } \\
\text { duct }\end{array}$ & Pressure outlet \\
\hline Bottom & No-slip wall \\
\hline Inlet & Moving wall \\
\hline
\end{tabular}

\section{RESULTS AND DISCUSSION}

\subsection{Temporal pattern for the free surface elevation}

The results for the free surface elevation have been computed using CFD simulation and linear wave theory. The study has been performed for the set of conditions listed previously in table 1 . It should be noticed that the free surface elevation has been captured at position $\mathrm{x}=22$ from the wave maker for an incident wave of $\mathrm{H}=0.06 \mathrm{~m}$ and $\mathrm{T}=2 \mathrm{sec}$. Comparing the run calculations in Figure 7 for the three types of wave makers, small differences are noticed between the piston type and the flap type generators.

For the plunger type great differences are mentioned from the period of time between $0-2.5 \mathrm{sec}$ where the elevation presents small amplitudes, after $2.5 \mathrm{sec}$ the free surface gets the same elevation as for the piston and flap wavemakers with a difference in phase.

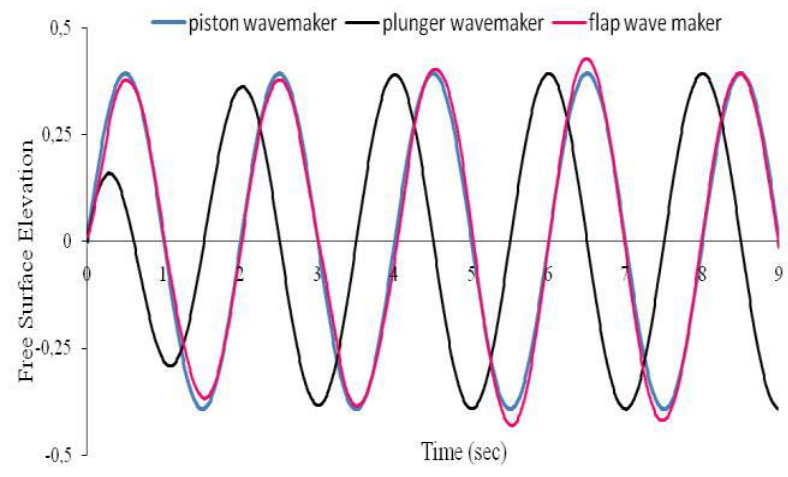

Fig.7 free surface elevation inside the numerical wave tank for $\mathrm{H}=0.06 \mathrm{~m}$ and $\mathrm{T}=2$.

The differences performed in Figure 7 are caused by the wave reflection when hitting the front wall of the OWC chamber. Also, the incident wave passes under the chamber's front wall this causes the water's free surface to adapt a non-uniform elevation.

\section{CONCLUSIONS}

As already mentioned, the main aim of this paper is to analyze the dynamic behavior OWC system with the use of numerical wave tank (NWT). To do so, three wave maker types were considered to generate regular waves inside a numerical wave tank which takes into consideration the biphasic (air and water) aspect of the water free surface interface. The results of this study have revealed that the water free surface elevation experience approximately the same pattern for the three wavemakers with small differences caused by the wave reflection and the interaction of the incoming wave with the OWC front wall.

\section{References}

1. Cruz, Sarmento, 2004, Ed. Instituto do Ambiente, Amadora, Portugal.

2. M. Fadaeenejad, R. Shamsipour, S.D. Rokni, C. Gomes, Renew Sust Energ Rev, pp.345-354, 29 (2014)

3. A.E. Marjani, F.C. Ruiz, M. A. Rodriguez, M.T.P. Santos, Energy, pp.1246-1256, 33 (2008)

4. J.M.P. Conde, L.M.C. Gato, Renew Energ, pp.26372644, 33 (2008)

5. S. Kim, KM. Kim, JC. Park, GM. Jeon, H. Chun, Int J Nav Arch Ocean, pp.188-197 (2016)

6. U. Şentürk, A. Özdamar, Math Comput Appl, pp. 630-640, 16,3 (2011)

7. M. Brorsen, J. Larsen, Coast Eng, pp.93-113 (1987).

8. C.W. Hirt, B.D. Nichols, J. Comput. Phys. pp.201225, 39 (1981).

9. R. G. Dean, R. A. Dalrymple, Prentice Hall, Inc (1984).

10. Galvin, Technical Report AB0440880, Coast Eng, (1964).

11. L. Anant, M. Elangovan, Int J Math and Comp Sc, (2008)

12. B. Bouali, S. Larbi, Energ Proced, pp. 565 - 573, 36 (2013) 